\title{
Food Security Status and Its Determinants among Rural Households in Oda Bultum District, West Hararghe Zone, Oromia National Regional State, Ethiopia
}

\author{
Ahmed Mohammed Abdurehim* \\ School of Agricultural Economics and Agribusiness, Haramaya University \\ PO box 138, Dire Dawa, Ethiopia \\ Habtamu Abaynew Ejigu \\ College of Agriculture and Natural Resource, Dilla University \\ PO box 419, Dilla, Ethiopia
}

\begin{abstract}
Food security is one of the critical concerns and top priority of policy agenda for developing countries. Having clear picture on food security status and its determinants helps policy makers to devise appropriate policies that enhance food security. Hence, this study aims to determine the food security status of the households, status, gap and severity of food insecurity among rural households and its determinants in Oda Bultum district of West Hararghe zone, Oromia National Regional State. The data for this study were collected from primary and secondary sources. Primary data were collected from randomly selected 365 sample households by using multistage sampling procedure and secondary data were obtained from various sources. The data were analyzed using descriptive statistics, Foster-Greer-Thorbecke (FGT) and probit model. The survey results indicated that $38.9 \%$ sampled households were food secured whilst $61.1 \%$ were food insecure. Further analysis of Probit regression revealed that; sex of household head, educational level, household size, donkey ownership, cash crop production, off/non-farm income, income, access to irrigation and frequency of extension contact significantly increased probability of being food secure. This study recommends that rural households should be encouraged to increase off/non-farm income, work on household size by applying family planning, increasing frequency of extension contact, increasing cash crop productivity, increasing access to irrigation, increasing income, donkey possession and improvement of the educational level for the household heads in order to enhance households' food security status in the study area.
\end{abstract}

Keywords: Food security, Agro-pastoralist, Sedentary farming, Probit, Oda Bultum

DOI: $10.7176 / \mathrm{JESD} / 12-17-03$

Publication date:September $30^{\text {th }} 2021$

\section{Introduction}

These days, food insecurity is a global problem. Acknowledging that, the world is struggling to address since decades back. However, it is still far away from a decisive victory. In this regard, FAO (2016) indicated that despite undeniable progress in reducing rates of undernourishment and improving levels of nutrition and health, about 800 million people are chronically hungry. Among 800 million globally under chronically hunger people, 239 million are from Sub-Saharan Africa (SSA) and nearly two billion people are affected by hidden hunger (WHO, 2016). Further, FAO (2016) predicts that the world will host about 653 million undernourished people even in 2030 if no additional efforts are made to promote pro-poor development.

Researches evidenced that Ethiopia is among the countries in SSA countries which has been repeatedly mentioned in connection with food security problem. UNDP (2018) also pinpointed that Ethiopia is among the poorest and most food insecure countries of the world where $23 \%$ of the population live below the poverty line. Temesgen et al. (2016) also estimated that an average of 4.5 million Ethiopians were left to emergency food handout from 2011 through 2015 due to climate related calamites.

An empirical study conducted on household food security situation in central Oromia region of Ethiopia reported that $37.93 \%$ of the investigated households were food insecure (Degefa and Furgasa, 2016). The study found out that the major factors constraining households' food production are high fertilizer price, shortage of farm land, erratic rainfall pattern, water logging, crop disease and insect pests, lack of improved seed supply, and lack of improved farm machineries. Specific to West Hararghe zone, Fekeda et al. (2015) conveyed that the majority $(67.1 \%)$ of households were food insecure.

However, there are significant variations among regions and among districts of a single region in the extent, cause, vulnerability and coping strategies against food insecurity (Yisihake et al., 2016). As a result, in order to combat threats of food insecurity by ensuring food security, detailed understanding of the socio-economic condition of the group affected by it, and the determinant factors and how households cope with the problem of food insecurity is critically important (NEPAD, 2013). 
As already stated above, the problems of food insecurity take particular forms in its extent, causes and consequences at different level of analyses. Despite the efforts made by the government of Ethiopia, WFP and other development partners, food insecurity problem remains a challenge in Ethiopia in general and in Oda Bultum district in particular. In line with this, Oda Bultum district is one of the food insecure districts, which the government has taken as a pilot district for the implementation of PSNP starting from 2005 up to now.

However, in this district there were few empirical studies conducted on households' food security status, its determinants and coping mechanisms based on the agro-ecology. Hence, this study was intended at filling this research gap by considering the livelihood of the district (both agro-pastoral and sedentary) to identify the factors contributes to household food security in Oda Bultum district. Therefore, this paper focused on food security status of households, status, gap and severity of food insecurity among rural households and its determinants in the rural parts of Oda Bultum district in West Hararghe Zone, Oromia National Regional State, Ethiopia.

\section{Methodology}

\subsection{Description of the study area}

The study was conducted in Oda Bultum District of West Hararghe Zone of Oromia National Regional State, Ethiopia. Geographically the district is located between $8^{0} 35^{\prime} 00^{\prime \prime}$ and $9^{\circ} 00^{\prime} 00^{\prime \prime}$ North Latitude and $40^{\circ} 33^{\prime} 00^{\prime \prime}$ and $41^{\circ} 20$ ' 00 " East longitude. The total area of the district is 130,712 hectare and $1218 \mathrm{~km}^{2}$. The distance of district from the capital city of Ethiopia, Addis Ababa is $372 \mathrm{kms}$ and $37 \mathrm{kms}$ far from the capital city of zone, Chiro. The total population of district was 216,746, of which 106,205 are men and 110,541 women. While $13,955(6.4 \%)$ are urban inhabitants, a further $202,791(93.6 \%)$ are rural. A total of 45,156 households were counted in the district. The temperature of the study area varies between $22^{\circ} \mathrm{C}-28^{\circ} \mathrm{C}$ with average $25^{\circ} \mathrm{C}$ and the annual average rain fall is around $1200 \mathrm{~mm}$. Mixed farming system (crop-livestock integration) prevails as dominant economic activity in the district. Depending on the agro ecological location (livelihood), households in the study area produce varying degree of mix of cereals, pulse, oil seed (groundnut) and livestock. Some household also grows cash crops such as coffee and vegetables to lesser extent with almost all households producing Jima/khat. Sorghum and maize were the two most dominant food crops (OBDAO, 2018).

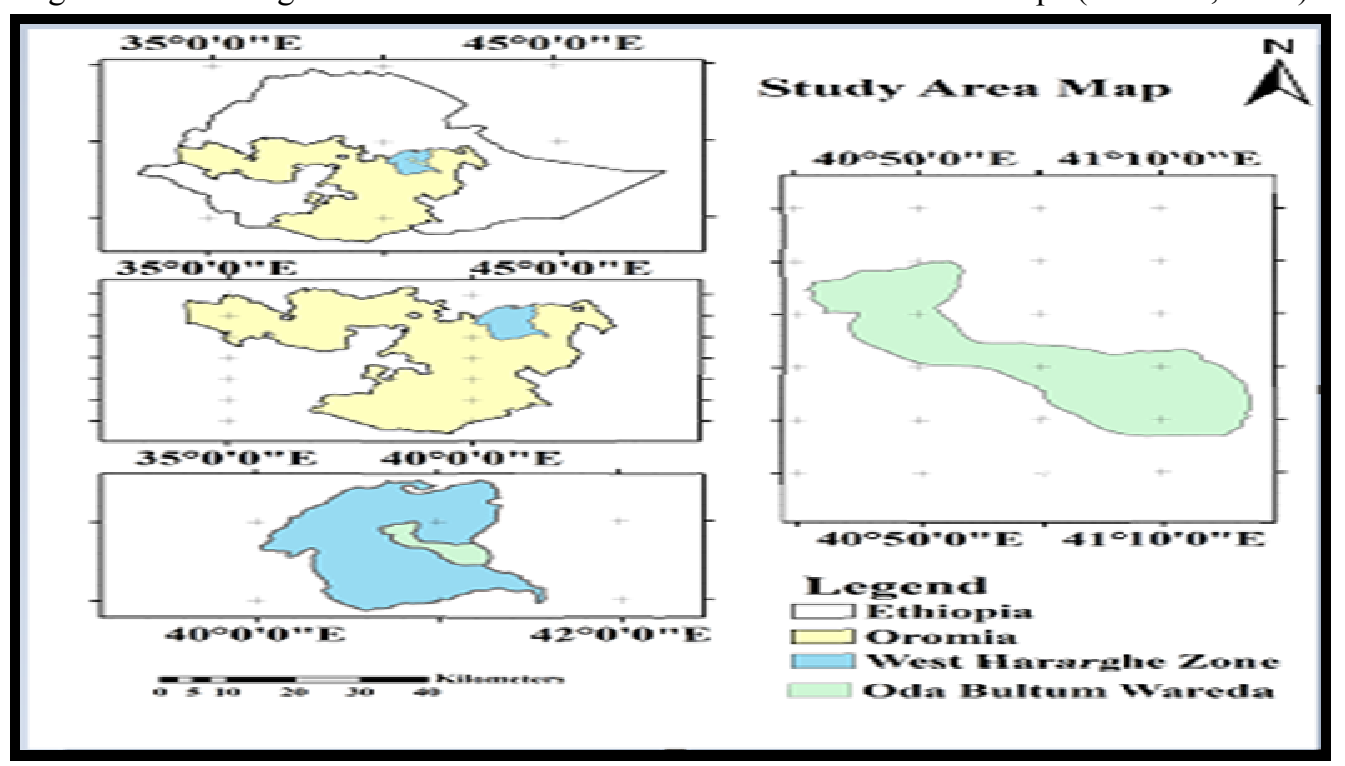

Figure 1: Geographic map of Oda Bultum district

Source: GIS based own construction (2019)

\subsection{Data Types, sources and methods of data collection}

In this paper both qualitative and quantitative types of data were used. The required data was generated from both primary and secondary sources. Primary data was collected by using household survey using structured questionnaire, focus group discussions and key informants' interview. While secondary data was collected from written documents including those from agro-pastoral and sedentary farming rural development bureaus and recent research works which are related to the study and study areas. It includes review of relevant journals, books, conference proceedings, academic thesis and dissertations and etc.

\subsection{Sampling techniques and sample size determination}

In this study, a multi-stage sampling procedure was applied to select representative sample respondents. In the 
first stage, the Oda Bultum district was purposively selected, because the district is more prone to food insecurity problems. In the second stage, based on livelihood types, the Kebeles (Gandas) of the district were stratified into two strata: agro-pastoral (having 17 Gandas/Kebeles) and sedentary farming (having 20 Gandas/Kebeles). In the third stage, two Kebeles (Gandas) from agro pastoral namely Bososo and Haroreti and two from sedentary farming namely Kolu and Oda Baso were randomly selected. Finally, after having a list of total number of households in each Kebele (Ganda), 365 households were selected by using simple random sampling with probability proportional to size: 172 households from agro-pastoral and 193 from sedentary farming households. The desired number of sample household was determined by using a formula developed by Yamane (1967). To determine the required sample size at $95 \%$ confidence level, with a 0.5 degree of variability and $5 \%$ level of precision, the following formula was used.

$$
n=\frac{N}{1+N(e)^{2}}
$$

where, $\mathrm{n}$ is sample size, $\mathrm{N}$ is the number of household and $\mathrm{e}$ is the desired level of precision. As 4,185 households are living in the four sample Gandas/Kebeles.

$$
\begin{aligned}
& n=\frac{4,185}{1+4185(0.05)^{2}} \\
& n=365 \text { households }
\end{aligned}
$$

Table 1: Total number of sampled HH heads

\begin{tabular}{llll}
\hline Gandas/Kebeles & Livelihood & Total household heads & Sample \\
\hline Bososo & Agro pastoral & 1,230 & 107 \\
Haroreti & Agro pastoral & 749 & 65 \\
Kolu & Sedentary farming & 1,246 & 109 \\
Oda baso & Sedentary farming & 960 & 84 \\
\hline Total & & $\mathbf{4 , 1 8 5}$ & $\mathbf{3 6 5}$ \\
\hline
\end{tabular}

Source: Oda Bultum district agriculture office report (2019)

\subsection{Analytical methods}

After the necessary data was collected, it entered to Statistical Package for Social Sciences (SPSS) version 20 and STATA V14.2. Then, descriptive, inferential and econometric methods of analysis were done to achieve the stated objectives of the study. Descriptive statistics is applicable to summarize and present the data in a manageable form. So, descriptive statistic such as percentage, frequency, mean and standard deviation was employed, and the output was presented using table. Moreover, t-test and chi-square test were used to know the existence of significant difference between food secure and insecure household groups in terms of important socio-economic, institutional and demographic factors for continuous and dummy variables, respectively.

To estimate the status, prevalence and severity of household food insecurity in the study area the Foster Greer Thorbeke (FGT) index was used. This model provides the three most commonly employed indices namely head count ratio, food insecurity gap and severity. These indices show the different situation of food insecurity. The head count ratio indicates the number of households whose consumption is below the bench mark; in this study $2200 \mathrm{kcal} / \mathrm{AE} / \mathrm{day}$ is the bench mark. Whereas, the food insecurity gap or depth measures how far the food insecure households are below the cut of value. On the other hand, squared food insecurity gap is more closely related to severity of food insecurity giving those further away from the minimum level by attaching a higher weight in aggregation than those closer to the subsistence level (Hoddinott, 2001).

Probit model was employed to identify the factors that affect households' food security status in the study area. Probit model was used over other alternative models because its interpretation is logical and clear to understand. Probit analysis is a specialized regression model of binomial response variables. Regression is a method of fitting a line to your data to compare the relationship of the response variable or dependent variable $(\mathrm{Y})$ to the independent variable $(\mathrm{X})$.

$$
Y_{i}=x \beta+u_{i}
$$

Where:

$$
\begin{aligned}
& Y_{i}=\text { food security status of the } \mathrm{i}^{\text {th }} \text { respondent (household) } \\
& X=\text { vector of determinants of food security } \\
& \beta=\text { vector of parameters of interest }
\end{aligned}
$$


$u_{i}=$ residuals of the $\mathrm{i}^{\text {th }}$ respondent of the household

A binomial response variable refers to a response variable with only two outcomes. The probit model assumes that the function $F$ follows a normal (cumulative) distribution,

$$
F(x)=\Phi(x)=\int_{-\infty}^{x} \phi(z) d z
$$

Where $\phi(z)$ is the normal density function,

$$
\phi(z)=\frac{\exp \left(-\frac{z^{2}}{2}\right)}{\sqrt{2 \pi}}
$$

Variance inflation factor (VIF) was used to detect the multicollinearity among the explanatory variables.

$$
\operatorname{VIF}\left(X_{j}\right)=\left(\frac{1}{1-R_{j}^{2}}\right)
$$

Hosmer-Lemshow test were also used to test the goodness of fit of the model.

In this study, sampled households were classified into food secure and food insecure groups based on kilocalories (kcal) consumed by the households using seven days recall method. Household caloric acquisition is a measure of the number of calories, or nutrients available for consumption by household members over a defined period of time. The principal person responsible for preparing meals were asked how much food was prepared for consumption from purchase, stock and/or gift/loan/wage over a period of time. In order to calculate households' daily calorie intake, the total households' calorie intake for the last seven days was divided by seven. Then, daily food energy consumption per adult equivalent is calculated by dividing each household's daily caloric consumption by the household members, adjusting for age and sex and then compared with daily recommended calorie intake, i.e., $2200 \mathrm{kcal} / \mathrm{AE} / \mathrm{day}$.

Household food security status (HFINS): It is a dichotomous dependent variable in the model taking a value 1 if the household is food secure and 0 otherwise. Household's food security status was determined by comparing total kilocalories consumed in household per adult equivalent per day with the daily minimum requirement of 2,200 kilocalories per adult equivalent per day. Households getting 2,200 Kcal/AE/day and above was

\begin{tabular}{|c|c|c|c|}
\hline Description of Variables & Types & Unit of measurement & Expected sign \\
\hline $\begin{array}{l}\text { Dependent variable: Household food } \\
\text { security status }\end{array}$ & Dummy & $\begin{array}{l}1 \text { - food secure, } \\
0 \text { - food insecure }\end{array}$ & \\
\hline \multicolumn{4}{|l|}{ Independent variables } \\
\hline Age of household head & Continuous & Years & - \\
\hline Sex of the household head & Dummy & 1 for male, 0 for female & + \\
\hline Educational status of household & Dummy & Years of schooling & + \\
\hline Livestock ownership & Continuous & TLU & + \\
\hline Number of Oxen & Continuous & Number & + \\
\hline Number of Donkey & Continuous & Number & + \\
\hline Size of cultivated land & Continuous & $\mathrm{Ha}$ & + \\
\hline Off/non-farm income & Continuous & ETB & + \\
\hline Household size & Continuous & $\mathrm{AE}$ & - \\
\hline Number of Livestock died in a year & Continuous & TLU & - \\
\hline Distance from market center & Continuous & $\mathrm{Km}$ & - \\
\hline Access to irrigation & Dummy & 1 if access, 0 if not & + \\
\hline Frequency of extension contact & Continuous & Number & + \\
\hline Access to credit & Dummy & 1 if access, 0 if not & + \\
\hline Types of farming activities & Dummy & $\begin{array}{l}1 \text { for sedentary farming, } 0 \\
\text { for agro-pastoral }\end{array}$ & + \\
\hline Cash crop production & Dummy & $\begin{array}{l}1 \text { if household produce cash } \\
\text { crop, } 0 \text { if not }\end{array}$ & + \\
\hline Total annual income & Continuous & ETB & + \\
\hline Membership to cooperative & Dummy & 1 for member, 0 if not & + \\
\hline
\end{tabular}
considered as food secure and otherwise food insecure.

Table 2: Summary of definition of variables and hypothesis

Source: literature reviewed (2019) 


\section{Results and Discussions}

\subsection{Household Food Security Status}

The result from the sampled 365 respondents indicated that $142(38.9 \%)$ and $223(61.1 \%)$ of the households of the study area were food secure and insecure, respectively. The maximum and minimum kilocalories consumed by a single adult in a day for food secure households were 3265.065 and $2206.087 \mathrm{kcals}$, and 2198.87 and 1561 kcals for food insecure households. The mean calorie intakes by food secure and food insecure sampled households were $2488.49 \mathrm{kcals}$ and $2008.3 \mathrm{kcals}$. The difference is significant at $1 \%$ significance level. The standard deviations for food secure and food insecure households were to be 193.24 and 133.23, respectively. The mean daily calorie intake per day per AE was $2195.11 \mathrm{kcal}$ which is below the national average of daily requirement of $2200 \mathrm{kcal}$ per day per adult equivalent for active and healthy life (Table 3 ).

Table 3: Mean differences test of daily calorie intake by food security status

\begin{tabular}{|c|c|c|c|c|c|}
\hline $\begin{array}{l}\text { Daily Energy Available per AE in } \\
\text { (Kcal) }\end{array}$ & $\begin{array}{l}\text { Food } \\
(\mathrm{N}=142)\end{array}$ & secure & $\begin{array}{ll}\text { Food } & \text { insecure } \\
(\mathrm{N}=223) & \\
\end{array}$ & $\begin{array}{l}\text { Total sample } \\
(\mathrm{N}=365)\end{array}$ & t-value \\
\hline Maximum & 3265.065 & & 2198.87 & 3265.065 & \\
\hline Minimum & 2206.087 & & 1561.00 & 1561.00 & $-28.08 * * *$ \\
\hline Mean & 2488.49 & & 2008.3 & 2195.11 & \\
\hline Standard deviation & 193.24 & & 133.23 & 283.3 & \\
\hline
\end{tabular}

Source: Own computation results based on survey data, 2020

Note: $* * *$ and $* * *$ show significance levels at $10 \%, 5 \%$ and $1 \%$, respectively.

\subsection{Incidence, Gap and Severity of Food Insecurity}

This section presents the food insecurity indices measured in this study; namely, head count ratio, food insecurity gap and severity of food insecurity:

Incidence (Head count ratio): This finding indicated that out of 172 agro pastoral sample households $76 \%$ (131 households) were food insecure and out of 193 sedentary farming sample households $47 \%$ ( 92 households) were also food insecure. This result showed that agro pastoral households more food insecure than sedentary farming households in the study area. Overall, $61.1 \%$ of the sampled households consume less than the minimum calorie requirement $(2200 \mathrm{Kcal})$.

Food insecurity gap: It measures the mean depth of food insecurity among the food insecure households by which the food security status of the food insecure households falls below the minimum level of calorie requirement. Food insecurity gap provides the possibility to estimate resources required to eliminate food insecurity through proper targeting. The result indicated that the food insecure household from the agro-pastoral requires $7.5 \%$ (165 kcal per adult equivalent per day) and also the sedentary farming household requires $3.3 \%$ (72.6 kcal per adult equivalent per day). The overall calculated value for food insecurity gap was found to be 0.053. This implies that, each food insecure household requires on average 5.3\% (116.6 kcal per adult equivalent per day) of the daily-recommended calorie to be food secured.

Severity of food insecurity: To address the most food insecure part of the sample households, severity of food insecurity was calculated. The result indicated that the inequality among food insecure households from agropastoral were $0.0104(1.04 \%)$ and the inequality among the food insecure household from the sedentary farming were also $0.037(3.7 \%)$. The overall survey result revealed that inequality among food insecure households were about $0.0069(0.69 \%)$ in the study area, implying that there was no much difference between food insecure household's daily calorie intake.

Table 4: Incidence, gap and severity of food insecurity

\begin{tabular}{llll}
\hline Household-group & \multicolumn{3}{c}{ FGT Indices } \\
\cline { 2 - 4 } (Livelihood) & Incidence & Gap & Severity \\
\hline Agro pastoral & 0.76 & 0.075 & 0.0104 \\
Sedentary farming & 0.47 & 0.033 & 0.0037 \\
\hline Overall sample & 0.611 & 0.053 & 0.0069 \\
\hline
\end{tabular}

Source: Own computation results based on survey data, 2020.

\subsection{Determinants of household food security status}

Prior to the estimation of the model parameters, detection and correction of multicollinearity and model specification were done. Variance inflation factor (VIF) was used to check multicollinearity problem between variables. Results of VIF showed that there was serious problem of multicollinearity among type of farming and lnincome of the explanatory variables, due to this reason the variable type of farming was excluded from the model because it was insignificant and replaced by the proxy variable agro ecology (Appendix Table 1). The result of link test $(\operatorname{Pr}>|z|=0.943)$ indicated that the model is appropriately specified (Appendix Table 2). 
Moreover, the result of Hosmer-Lemeshow test $($ Prob $>$ chi2 $=1.0000)$ indicated that the null hypothesis test of goodness of fit of the model was accepted. It suggested that the error term follows standard normal cumulative distribution function, thus the probit model was fitted for the data (Appendix Table 3).

Estimates of the parameters of the variables expected to determine the households' food security status were presented in Table 3. The goodness-of-fit was tested by the Log likelihood ratio (LR) test. The result showed that the chi-square value was 407.34 and the pro>chi2 was 0.000 , this means that $\chi^{2}$ is statistically significant and the model displays a good fit. The Pseudo $R^{2}$ of the model is also 0.83 , implying that $83 \%$ of the variation in the model was explained by the independent variables. This verifies that the model has a good fit to the data and explained significant non-zero variations in factors influencing households' food security status.

Probit regression model was used to identify the determinants of households' food security status in the study area. Accordingly, variables hypothesized to have influence on the household's food security status in were fitted in the model. Therefore, out of 18 variables included in the model, nine (9) variables were statistically significant. Namely, sex of household head, educational level of the household head, donkey holding, off/non-farm income, household size, income (ln), access to irrigation, frequency of extension contacts and cash crop production.

Sex of household heads: It had significant and positive relationship with the household food security status. It was significant at 5 percent probability level. The result showed that male headed households were more food secure than female headed households. Other factors remaining constant, food security of male household headed increased by 15.9 percent than female headed households. The possible explanation was the differential access to production resources where male had more access to production resources like cultivated land than females (Table 5). This result similar with the result of Greenwell and Pius (2012).

Educational level of household head: It had a positive and significant relationship with household food security at $10 \%$ significance level. Other variables remaining constant, an increase in the level of education by one year of school increases the probability that the household become food secure by 3.3 percent. That is, the more the educational levels of the household head, the higher the probability that the household become food secure (Table 5). This finding is similar with the findings of Ehebhamen et al. (2017).

Donkey ownership: It had positive relationship with food security status and significant at 1\% probability level. Other variables remaining constant, an increase in the number of donkey owned by one increases the probability that the household become food secure by 21 percent. The household who has more donkey they generate more income that increase food security, because donkey is used as the main transportation means, helped households to produce more by themselves or to earn income by renting their donkey to others which in turn helped households to access food in rural households (Table 5). This result is in line with the results of Avornyo et al. (2015).

Off/non-farm income: It had significant and positive relation with the food security status at $5 \%$ probability level and indicating that households engaged in off/non-farm activities have better chance to be food secure. This might be because households engaged in off/non-farm activities are more endowed with additional income and more likely to escape food insecurity. The marginal effect result shows that, a birr increases of income from off/non-farm activities, increasing the probability of households to be food secured by 0.01 percent. The explanation is that in this particular study, the household who solely depend on farm activities have inadequate income to purchase farm inputs and fulfill family needs and thus, they found to be food insecure. This shows that off-farm and /or non-farm job opportunities play prominent role in managing household food security in the district (Table 5). This finding is in line with the findings of Ahmed (2015).

Household size: It had significant and negative relationship with food security status at $1 \%$ probability level. The negative sign shows that the probability of becoming food secure is low for households where household size is high. Other variables remaining constant, as the household size increases by an AE, the probability that the household became food secure decreases by 36 percent (Table 5). The result is in line with the findings of (Stephen and Samuel, 2013; Indris, 2012; Muche et al., 2014).

Total annual income excluding off/non-farm income (Inincome): It had positive relationship with food security status and significant at $1 \%$ probability level. Other variables remaining constant, an increase in the income of the household by one birr the probability that the household become food secure increase by 165 percent. The household who has high income were more food secure than the households who have less income (Table 5). This result is in line with the results of (Ejigayehu and Edriss, 2012).

Access to irrigation: It had a significant influence and positive relationship with household food security at $1 \%$ probability level. This implies that the probability of being food secured households increases with access to irrigation. The marginal effect result show that, as compared to household who did not access to irrigation, the probability of the access to irrigation households to become food secure was higher by 46.8 percent. Irrigation, as one of the technology options available, enables smallholder farmers to directly produce consumable food grains and/or diversify their cropping and supplement moisture deficiency in agriculture and helps to increase production and food consumption (Table 5). This finding is similar with the result of (Van der Veen and Tagel, 
2011).

Frequency of extension contact: It had a significant and positive relationship with household food security at $5 \%$ probability level. This implies that the probability of being food secured households increases with access to frequency of extension contact. The marginal effect result show that, as compared to household who did not access to frequency of extension contact, the probability of the access to frequency of extension contacts households to become food secure was higher by 10.6 percent. More frequent extension contact enhances households' access to better crop production techniques, improved input as well as other production incentives, and this helps to improve food energy intake status of households (Table 5). This finding is in line with the result of (Hussein and Janekarnkij, 2013).

Cash crop production: It had a significant influence and positive relationship with household food security at $1 \%$ probability level. This implies that the probability of being food secured households increases with production of cash crop. Therefore, those households who produce cash crops being in a better position than those who did not produce cash crops. The marginal effect result show that, as compared to household who did not produce cash crop, the probability of the cash crop producer household to become food secure was higher by 60.8 percent. Based on the above results, cash crop production is important in ensuring food security of the farm households (Table 5). This finding is similar with the findings of Fekede et al. (2016) and Nasir (2018). Table 5: Determinants of food security status: Probit regression model

\begin{tabular}{lccc}
\hline Variable & Coefficient & Standard error & Marginal effect \\
\hline Age of household head & 0.0013 & 0.027 & 0.0003 \\
Sex of the household & $0.807^{* *}$ & 0.410 & 0.159 \\
Educational Level & $0.159^{*}$ & 0.091 & 0.033 \\
Livestock ownership & -0.105 & 0.124 & -0.022 \\
Number of Oxen & -0.185 & 0.277 & -0.039 \\
Number of Donkey & $1.005^{* * *}$ & 0.382 & 0.21 \\
Size of cultivated land & 0.425 & 0.670 & 0.089 \\
Off/non-farm income & $0.0004^{* *}$ & 0.0002 & 0.0001 \\
Household size & $-1.727^{* * *}$ & 0.491 & -0.360 \\
Number of Livestock died in a year & 0.255 & 0.423 & 0.053 \\
Distance from market & -0.018 & 0.0099 & -0.004 \\
Lnincome & $7.935^{* * *}$ & 2.065 & 1.65 \\
Access to irrigation & $1.69^{* * *}$ & 0.547 & 0.468 \\
Frequency of extension contact & $0.510^{* *}$ & 0.257 & 0.106 \\
Access to credit & -0.184 & 0.347 & -0.037 \\
Membership to Coop & 0.227 & 0.443 & 0.048 \\
Cash crop production & $2.69^{* * *}$ & 0.512 & 0.608 \\
Agro ecology & 0.712 & 0.479 & 0.148 \\
Constant & -80.773 & 19.456 & \\
\hline Log likelihood & -40.27 & & \\
Number of observations & 365 & & \\
LR chi2 (17) & 407.34 & & \\
Prob > chi2 & 0.000 & & \\
Pseudo R & 0.83 & & \\
Sensitivity & 0.81 & & \\
Specificity & 0.68 & & \\
\hline Source: Own computation & & & \\
\end{tabular}

Source: Own computation results based on survey data, 2020.

Note: $* * *$ and $* * *$ show significance levels at $10 \%, 5 \%$ and $1 \%$, respectively.

${ }^{1}$ Correctly predicted food secure group based on 0.5 cut value

${ }^{2}$ Correctly predicted food insecure group based on 0.5 cut value

The predicted $\mathrm{Y}$ hat $[\mathrm{Y}=\operatorname{Pr}(\mathrm{HHFS}=1)]$ was 0.127 , suggesting that the success probability of being food secure by the sample households was about $12.7 \%$.

The result of Hosmer-Lemeshow test (Prob $>$ chi $2=1.0000)$ indicated that the null hypothesis test of goodness of fit of the model was accepted. It suggested that the error term follows standard normal cumulative distribution function, thus the probit model was fitted for the data.

\section{Conclusions and Recommendations}

Study area is considered as food insecure district by the government; in line with this, the result of the study shows that $61.1 \%$ of the surveyed households were unable to get the minimum daily energy requirement. Moreover, the mean energy gained by food secure and food insecure households were 2488.49 and 2008.3 
$\mathrm{kcal} / \mathrm{day} / \mathrm{AE}$, respectively. The food insecurity gap reported that the food insecure households can be brought to the minimum subsistence energy requirement level $(2200 \mathrm{kcal})$, on average, if $116.6 \mathrm{kcal}$ per adult equivalent per day $(5.3 \%$ of the food insecurity line) their caloric energy is fulfilled. The severity index indicated that about $0 . .69 \%$ of the food insecure households were severely food insecure.

Sex of household head had positive and significant effect on food security status. This means the probability of being food secure was high for male headed households. Therefore, in order to increase the food security status of households in the study area priority should be given to female headed households. Furthermore, strengthening capacity of females through education should be an integral part of the involvement.

Education level of household head showed positive and significant effect on food security status of the households. The education of household head could lead to awareness of the possible benefits of making agriculture a modern enterprise through advanced technological inputs, enhancing farmers to follow instructions on fertilizer packs and shall be used to diversification of household incomes that, in turn, would enable household food supply appropriately, due to this the government and concerned NGO need to work on the improvement of educational status of households especially the formal education.

Donkey ownership was the significant determinant and positively related with households' food security. Donkeys are critical for food security due to its integral part related with transportation. Household having enough number of donkeys is more food secure than the one has no donkey. Moreover, it was observed from the field survey that as coping mechanisms, rural households sell their donkey during hard times to survive. Losing donkey made them very difficult to recover even during the normal seasons. This forces household to be food insecure in the next unpromising season since they miss their integral part related with transport and income generate by renting their donkey to others. Due to this reason households should be supported to have donkey by enhancing income to overcome the household's capital problem, there have to donkey restocking program for households who lost their donkey from drought or any other shock.

Off/ non-farm activities are found to be positively and significantly influence food security status of the households. Because of it is crucial for expansion of the sources of farm house-holds' livelihoods. In this, case modern of production by providing the households with an opportunity to use the required inputs. It also minimizes the danger of food shortage during the time of unanticipated crops failure through food purchases. As a result, a great chance of famishment (a state of extreme hunger resulting from lack of essential nutrients over a prolonged period) for themselves and their families during periods of chronic or transitory food insecurity has avoided and reduced largely. In this regard, promoting off/non- farm activities can help rural households in solving capital problem, farm inputs, use for trade, etc. Hence, this calls for enhancing and expanding the off/non-farm activities for the farm households in the study areas, and this should be one of the areas of intervention and policy option.

Household size showed negative and significant influence on food security status. The higher size of the household the more the pressure on the consumption than on the labor that contributes to production. Thus, a negative relation between the household size and food security status, due to this reason the concerned body including the government should work on the family planning.

Cash crop production found to have a significant influence and positive relationship with household food security. Therefore, those households who produce cash crops being in a better position than those who did not produce cash crops. Because, cash crop production is important to ensuring food security of the rural households, thus concerning sectors of government as well as NGOs has to focus on its improvement.

Income of household head had positive and significant effect on food security status. This means the probability of being food secure was high for households have high income. Therefore, in order to increase the food security status of households in the study area, the government, NGOs and other concerned bodies should give the priority and work on the issue (activities) that can generate more income than before.

Access to irrigation found to have a significant influence and positive relationship with household food security status. This implies that the households who access to irrigation being food secured than households did not access to irrigation. Irrigation, as one of the technology options available, enables smallholder farmers to directly produce consumable food grains and/or diversify their cropping and supplement moisture deficiency in agriculture and helps to increase production and food consumption. Due to this reason the government and different NGOs should support rural households to access irrigation, especially by providing (outing) undergrounding water that can community used for irrigation all season.

Frequency of extension contact found to have a significant and positive relationship with household food security status. The food security of households increases with access to frequency of extension contact. The household who gets access to frequency of extension contact better food secure than who did not get. More frequent extension contact enhances households' access to better crop production techniques, improved input as well as other production incentives, and this helps to improve food energy intake status of households, so the government should hire skilled and enough development agent to increase frequency of extension contact and awareness for rural households. 


\section{References}

Ahmed Mohammed. (2015). Determinants of house hold food security and coping strategies: The case of Bule Hora district, Borana zone, Oromia, Ethiopia. European Journal of Food Science and Technology, 3(3): 3044.

Avornyo, F. K., Teye, G. A., Bukari, D. and Salifu, S. (2015). Contribution of donkeys to household food security: a case study in the Bawku Municipality of the Upper East Region of Ghana. Ghana Journal of Science, Technology and Development, 3(1):15-24.

Ehebhamen, O., Obayelu, A., Vaughan, I. and Afolabi, W. (2017). Rural households' food security status and coping strategies in Edo State Nigeria. International Food Research Journal, 24(1): 333-340.

Ejigayehu Sisay and Edriss, A.K. (2012). Determinants of food insecurity in Addis Ababa City, Ethiopia. Journal of Economics and Sustainable Development, 3(3): 8-15.

FAO (Food and Agriculture Organization of the United Nations). (2016). Situation report on challenge facing agriculture and food security in Ethiopia. FAO, Rome, Italy.

Fekeda Gemechu, Lemma Zemedu and Jemal Yousuf. (2015). Determinants of farm household food security in Hawi Gudina district, West Hararghe zone, Oromia Regional State, Ethiopia.

Fekede Gemechu, Lemma Zemedu and Jemal Yousuf. (2016). Determinants of farm household food security in Hawi Gudina district West Hararghe Zone, Oromia region, Ethiopia. Journal of Agricultural Extension and Rural Development, 8(2): 12-18.

Frankenberger, T.R. (1992). Indicators and data collection methods for assessing household food security. Household food security: concepts, indicators and measurement, technical review, UNICEF and IFAD, Rome.

Furgasa Derara and Degefa Tolosa. (2016). Household food security situation in central Oromia, Ethiopia: cases study from Becho wereda in south West Shewa Zone. Global Journal of Human Social Science, 16(2):1-17.

Greenwell, C.M. and Pius, C. (2012). 'Estimating Effects of Constraints on Food Security in Malawi: Policy Lessons from Regressions Quantiles', Applied econometrics and International Development 12(2).

Hussein, W. and Janekarnkij, P. (2013). Determinants of rural household food security in Jigjiga District of Ethiopia. Kasetsart Journal of Social Science, 34:171-180.

Indris Siraje. (2012). Assessment of food insecurity, its determinants and coping mechanisms among pastoral households of Afar National Regional State, the case of Chifra district. An MSc thesis presented to the School of Graduate Studies of Haramaya University.

Mequanent Muche, Birara Endalew and Tesfalem Koricho. (2014). Determinants of Food Security among Southwest Ethiopia Rural Households. Asian journal of Agricultural Research, 2014: ISSN 1819-1894, Malaysia.

Nasir Ahmed. (2018). Food security and coping strategies of rural households: the case of Oda Bultum district, West Hararghe Zone, Oromia National Regional State, Ethiopia. MSc Thesis, Haramaya University, Haramaya, Ethiopia.

NEPAD (New Partnership for Africa's Development). (2013). African agriculture, transformation and outlook. November 2013. NEPAD, Addis Ababa, Ethiopia.

OBDAO (Oda Bultum Administrative Office). (2018). Annual report, Oda Bultum District administrative office, West Hararghe, Ethiopia.

Stephen, F. and Samuel, A. (2013). Comparative study of determinants of food security in rural and urban households of Ashanti region, Ghana. Int J Econ Manage Sci, 2(10):29-42.

Temesgen Kebede, Jema Haji, Belaineh Legesse, and Girma Mamm. (2016). Evaluation of Rural Households' Food Security through Resilience Indicators: Ethiopian Institute of Agricultural Research (EIAR).

UNDP (United Nations Development Program). (2018). Ethiopia's Process towards Eradicating Poverty: Implementation of the Third United Nations Decade for the Eradication of Poverty, Addis Ababa, Ethiopia.

Van der Veen, A. and Tagel Gebrehiwot. (2011). Effect of policy interventions on food security in Tigray, northern Ethiopia.

WHO (World Health Organization). (2016). Global database on the Implementation of Nutrition Action (GINA) Programmes. https:/extranet.who.int/nutrition/gina/en/programmes/.

Yisihake Ergicho, Fisseha Asmera and Solomon Tilahun. (2016). Determinants of food insecurity and coping mechanisms among rural farm household the case of Shashogo and East Badewacho districts, Hadiya zone, South Nation Nationalities People Region, Ethiopia. International Journal of Science and Research, 5(11): $1155-1161$. 


\section{APPENDICES}

Appendix Table 1: Multicollinearity test

\begin{tabular}{lll}
\hline Variable & VIF & $1 /$ VIF \\
\hline TOFA & 15.00 & 0.066672 \\
LNINCOM & 10.12 & 0.098814 \\
DISTMRKT & 8.55 & 0.116943 \\
HHS & 8.53 & 0.117207 \\
LVTKOWN & 5.91 & 0.169174 \\
SCULND & 3.57 & 0.279802 \\
FRECON & 2.85 & 0.350558 \\
NOXO & 2.67 & 0.374528 \\
MEMTACOP & 2.31 & 0.432703 \\
CASHCP & 2.12 & 0.472632 \\
ACTIRG & 2.09 & 0.478101 \\
NLVD & 1.77 & 0.563817 \\
NODO & 1.75 & 0.573002 \\
EDUCHH & 1.51 & 0.661703 \\
AGEHH & 1.40 & 0.715375 \\
OFRMI & 1.26 & 0.792824 \\
SEXHH & 1.14 & 0.874301 \\
ACTCRDT & 1.06 & 0.945193 \\
\hline Mean VIF & 4.08 & \\
\hline
\end{tabular}

Source: Model output, 2020

Appendix Table 2: Link test of model specification Ho: The model is correctly specified

\begin{tabular}{lllllll}
\hline HHFS & Coef. & Std. Err & $\mathrm{Z}$ & $\mathrm{P}>|\mathrm{Z}|$ & {$[95 \%$ Conf. } & Interval] \\
\hline hat & 1.000511 & 0.1443005 & 6.93 & 0.000 & 0.7176873 & 1.283335 \\
Hatsq & 0.0067038 & 0.0938469 & 0.07 & 0.943 & -0.1772328 & 0.1906404 \\
Cons & -0.0080437 & 0.1937087 & -0.04 & 0.967 & -0.3877058 & 0.3716184 \\
\hline
\end{tabular}

Source: Model output, 2020

Appendix Table 3: Hosmer-Lemeshow test

Probit model for HHFS, goodness-of-fit test

Ho: The error follows normal cumulative distributions

\begin{tabular}{l|l}
\hline Number of observations & 365 \\
Number of covariate patterns & 365 \\
Pearson chi2 (345) & 87.19 \\
Prob $>$ chi2 & 1.0000 \\
\hline
\end{tabular}

Source: Model output, 2020 